Institute for Health Transformation, Deakin University, Burwood, Australia

2 Menzies Institute for Medical Research, University of Tasmania, Hobart, Australia

3 School of Environment, Resources and Sustainability, University of Waterloo, Waterloo, ON, Canada

Correspondence to: $\mathrm{M}$ Hensher martin.hensher@deakin.edu.au Cite this as: BMJ 2020;371:m4168 http://dx.doi.org/10.1136/bmj.m4168 Published: 17 November 2020
HEALTH IN THE ANTHROPOCENE

\section{Can healthcare adapt to a world of tightening ecological constraints? Challenges on the road to a post-growth future}

\section{Martin Hensher and Katharine Zywert examine some of the difficult changes that healthcare systems will need to make in the Anthropocene epoch}

Martin Hensher, ${ }^{1,2}$ Katharine Zywert ${ }^{3}$

Healthcare has been an integral part of the rapid growth in economic output, population, and use of resources seen in recent decades. Expenditure on healthcare has consistently grown faster than the overall rate of growth of gross domestic product (GDP) in high income countries and, more recently, in middle income countries too. ${ }^{1}$ Our achievements and technologies have brought unparalleled prosperity to many people, and greatly improved life and health prospects to most. Yet the accompanying changes we have wrought on the Earth system have been so profound that they qualify as a new geological epoch $^{2}$-the Anthropocene-and may threaten humanity's future wellbeing and prosperity.

As the planetary boundaries within which humans can thrive are increasingly transgressed, ${ }^{3}$ beneficial economic growth has given way to "uneconomic growth."4 We analyse how healthcare systems might prepare themselves for the changing conditions of the Anthropocene given the urgent need to decouple economic growth and prosperity from their damaging environmental effects, while preserving the health and wellbeing gains achieved through the transition to modernity. ${ }^{5}$

\section{Decoupling growth and resource use}

Historically, the growth of economic activity was accompanied by increasing consumption of natural resources, alongside rising negative effects on the natural environment. ${ }^{2}$ In more recent years, however, hopes have risen that it may be possible to "decouple" or "dematerialise" GDP growth from environmental harms.

Decoupling may be absolute or relative. Relative (or weak) decoupling occurs when the rate of GDP growth is higher than the rate of growth in material and energy consumption and environmental impacts. ${ }^{6}$ Absolute (or strong) decoupling occurs when continued economic growth is accompanied by an absolute decrease in use of materials and energy and in environmental impacts. ${ }^{6}$ If humanity is to minimise the extent of future warming from climate change it must achieve sufficient absolute decoupling-sufficient to bring humanity back within the planetary "safe operating space." 36

The United Kingdom has achieved an absolute decoupling of $\mathrm{CO}_{2}$ emissions from economic growth over the past decade, with emissions falling by $29 \%$ between 2010 and 2019 even while the economy grew. Yet this has not been sufficient to put the UK on track to meet its required carbon targets-a further $31 \%$ reduction is needed by 2030, but government projects only a further $10 \%$ cut. $^{7}$

At a global scale, several planetary boundaries have already been breached. ${ }^{3}$ For example, the rate of species extinction is tens to hundreds of times faster than the average for the past 10 million years, with around $25 \%$ of animal and plant species at risk of extinction, breaching biosphere integrity and posing serious risks to food security. ${ }^{8}$ Other boundaries are also at significant risk of breaching, most notably climate and atmospheric $\mathrm{CO} 2$ concentrations. ${ }^{3} \mathrm{Box} 1$ summarises three competing visions of a sustainable economy that might deliver sufficient absolute decoupling.

Box 1: Economic models for decoupling economic growth and environmental harm ${ }^{1}$

- Green growth-The increase in economic output lowers total environmental footprint through growth can be pursued as a policy goal but only in ways that will reduce or not worsen environmental harms ${ }^{9}$

- Steady state economy-Does not pursue economic growth (either positive or negative) as a goal but instead seeks "to sustain a constant, sufficient stock of real wealth and people for a long time" 10 by maximising human wellbeing and flourishing within a carefully determined and sustainable level of consumption of natural resources

- Degrowth-Active contraction in overall economic activity to a material scale and footprint consistent with remaining inside planetary boundaries. ${ }^{11}$ Degrowth may be voluntary (planned and deliberate contraction) or involuntary (resulting from economic shocks such as the covid-19 pandemic or forced by environmental constraints)

Empirical studies provide strong evidence that many high income countries have already achieved relative decoupling of GDP growth from material throughput. ${ }^{612} 13$ Some high income countries may also have achieved absolute decoupling for short periods, ${ }^{7}$ although this seems to have been counterbalanced by strongly coupled growth in fast growing middle income countries, driving overall increases in material and environmental effects. ${ }^{9}$ Hopes that global greenhouse gas emissions had peaked in 2015 and 2016 were dashed when they resumed their upward trajectory in $2017 . .^{12}$ continuous improvements in efficiency; economic 
Recent studies suggest that absolute decoupling in high income countries was more illusory than real. Real material effects were hidden by moving industrial production to the developing world, ${ }^{6}$ inflation of GDP through growth of the non-productive financial sector, ${ }^{613}$ and "rebound" effects whereby improvements in resource efficiency allow greater quantities to be produced and consumed as costs decrease. ${ }^{1214}$

Meanwhile, initial attempts to estimate how much material throughput needs to be reduced to remain within planetary boundaries are also not reassuring. Few countries satisfactorily meet basic needs without using natural resources at levels well beyond safe biophysical boundaries. ${ }^{15}$ Thus, several studies conclude that sufficient absolute decoupling of economic activity from environmental impacts is simply not consistent with continued GDP growth, whether "green" or otherwise. 61214

\section{Challenges of transition to a post-growth world}

Changes to Earth systems and the climate, combined with the changes to global economic systems needed to deliver sustainability, will drastically alter the world in which healthcare operates. ${ }^{16}$ In the transition to a sustainable society, healthcare may need to adapt substantially to continue to function within a new social-ecological system that is defined by

- Less availability of material resources and energy for medical procedures, technologies, pharmaceuticals, and infrastructure

- Reduced societal complexity overall, translating into reduced complexity within healthcare systems

- A return to more place bound ways of living as transport costs rise, local production increases, and life becomes relocalised, and

- Less space for future growth of healthcare. 4516

These transitions could imply numerous complex structural and cultural challenges for healthcare. Societies must preserve those components of modern healthcare that generate the greatest returns for population health, such as vaccination programmes, health promotion activities (eg, campaigns to reduce smoking), and dietary interventions to prevent non-communicable diseases. ${ }^{17}{ }^{18}$ In healthcare, reducing economic complexity could limit the scope of available interventions or technologies, or even eliminate whole tiers of specialised care. ${ }^{16}$ The challenges associated with this transition are certainly onerous but not impossible.

In 1990, Cuba was cut off from international trade and supply of fossil fuels, following the collapse of the Soviet Union, on which it was heavily dependent. However, the country was able to rapidly enforce lifestyle changes and prioritised investments in community based care and education for primary care professionals. Through strong public health measures, Cuba developed a pared down but highly effective universal healthcare system. Even in a time of crisis, this approach ensured that infant and child mortality rates, maternal mortality, and life expectancy remained constant or improved. ${ }^{19}$

It would be naive to suggest that real reductions in healthcare resource use and consumption can occur without risk of pain or political conflict. Cuba's success from the perspective of population level health outcomes was experienced as "a time of exceptional hardship" during which structural and cultural changes to healthcare occurred only "as a matter of despair."19 Yet overuse, overdiagnosis, and overtreatment are serious problems in modern healthcare systems, ${ }^{20}$ and carefully targeting reductions to eliminate overuse could improve healthcare outcomes, not undermine them. ${ }^{21}$
Ironically, Anthropocene pressures might provide the truly hard constraint that has so far been missing in efforts to transform healthcare systems to deliver real value and to drive out endemic low value and harmful care. ${ }^{1}$

The transition to a post-growth economy would also offer an opportunity to act effectively on the social determinants of health. Risk factors for non-communicable diseases that have proved hard to modify under a growth economy might become the centre of efforts to reduce harmful and unnecessary consumption-ranging from food, alcohol, addictive products, and physical inactivity to the health impacts of pollution in all its forms. ${ }^{22}$ WHO's 2019 assessment of the top 10 threats to global health highlighted how many of the greatest health challenges are intimately related to overconsumption, pollution, and climate change. ${ }^{23}$

Modern healthcare is technologically intensive and dependent. Rightly or wrongly, technological innovation in healthcare has become heavily conflated with commercial entrepreneurial business models. However, the real contributions of private versus public investment to healthcare innovation have been increasingly questioned, ${ }^{24}$ and existing for-profit models have proved incapable of tackling the problem of antimicrobial resistance, ${ }^{25}$ which poses the greatest real threat of medical-techological regress under all economic models. A post-growth economy would reduce the economic incentives for corporations to invest in high technology healthcare. We might instead see more time and energy invested in social innovations that make existing public health and community resources function more effectively. ${ }^{26}$

Meanwhile, the interaction of developments at the frontiers of healthcare technology with social, economic, and environmental sustainability may be complex and unpredictable. If fundamental breakthroughs are made in extending human lifespans, ${ }^{27}$ these might pose deep tensions for society as they could slow down or even reverse long term trends towards global population stabilisation. ${ }^{28}$

\section{How to respond?}

Societies must consider how to promote health and resource healthcare in the absence of economic growth. States will have to develop new mechanisms for delivering public goods, redistributing resources, and reducing inequities in ways that do not depend on growth. ${ }^{29}$ The burden of taxation will need to be shifted away from citizens and towards corporations and damaging activities. Carbon and "green" taxes to discourage polluting behaviour will need to be combined with taxes on health damaging industries, while subsidies for health and environmentally damaging industries will need to be eliminated. Coordinated international action will be required to eliminate tax havens and tax avoidance and evasion by the wealthy.

Health can be improved and healthcare costs reduced by tackling the social determinants of health through universal basic income, ${ }^{30}$ job guarantees, or living wage policies. ${ }^{31}$ Beyond the state, civil society and community reciprocity must be reinvigorated. The local mutual aid networks that have emerged to care for vulnerable community members during covid-19 are one example of this starting to emerge. ${ }^{32}$

Many health systems have already begun work to reduce the environmental impact of healthcare. However, ensuring that healthcare systems are resilient and adaptable in the face of these emerging problems will require much more than simply "greening" the supply chain. 
Our increasing understanding of the simultaneous harms of overtreatment to both human health and the natural environment is likely to require cultural change among health professionals and wider society. We will need to develop a culture and ethic which prizes "doing enough" rather than trying to "do everything possible." 33

The covid-19 pandemic has opened up unexpected spaces for innovation and cultural change for health professionals and wider society alike, which offer opportunities to drive changes in health and healthcare towards a more sustainable future. Health workers have found new ways to expand collaborations and to abandon ineffective ways of working. ${ }^{34}$ They have renewed their commitment to core professional values in the face of adversity; while all healthcare systems now have a renewed appreciation of the central importance of strong public health capabilities.

In society at large, we might see more focus on ritual and renewed community bonds as important sources of meaning surrounding birth, illness, and death, with changed cultural expectations of healthcare. A reduced reliance on instititutional care might begin to emerge. For example, "care farming" has been shown to improve physical, social, and psychological outcomes for participants while also restoring local ecosystems. 935 Over time, intergenerational co-housing of families may increase to promote collective care of older people and children rather than current models of residential aged care.

The unfolding covid-19 pandemic is giving our societies a close encounter with fragility and vulnerability in complex social and economic systems, but the post-pandemic recovery period is an opportunity to transform in the light of hard learnt lessons on the value of sufficiency and resilience (box 2). Many of the lessons of covid-19 overlap with recommendations for cultural and institutional change in the Anthropocene. ${ }^{16}$ They include the importance of strengthening public and population health services and capabilities, if necessary in preference to clinical services; the need for every country to establish publicly owned manufacturing capability for pharmaceuticals, vaccines, and essential medical equipment and supplies; and to equip all health professionals with the knowledge and flexibility to provide safe and effective care under quite different levels of resourcing and adverse circumstances, not just for an idealised "best practice."

\section{Box 2: Post-covid economics: decoupling, depression, or degrowth?}

The economies of most countries have shrunk in the wake of covid-19, with steep rises in unemployment and falling incomes. Left unmanaged, a global post-covid economic depression would undoubtedly be damaging to health and wellbeing.

After rapid falls early in the pandemic, carbon dioxide emissions have returned to near pre-pandemic levels in many countries. ${ }^{36}$ Those pursuing decoupling are therefore calling urgently for the post-covid recovery to be driven by new, sustainable economic models.

Adherents of green growth argue that stimulus and recovery packages offer an opportunity to invest in deep reductions in emissions while also supporting wellbeing and equity-but only if comprehensive "green" recovery packages are implemented systematically in the coming months and replace the crisis response packages that have so far sought to support existing economic activity. ${ }^{37}$

Massive increases in unemployment during the pandemic have also driven wider interest in concepts such as universal basic income and reduced working weeks-ideas that are central to steady state and degrowth economic models. ${ }^{10} 1138$

We must embrace the full complexity of the changes facing healthcare, resist the urge to simplify or to preserve the status quo, and engage in difficult conversations that cross ideological and professional divides. If green growth proves unfeasible, societies and their healthcare systems face two paths-deliberate simplification and reduced resource use to achieve post-growth sufficiency or sticking with growth amid increasing risks of cascading environmental degradation and collapsing systems that will force involuntary simplification. We need to find a benevolent path through the problem that allows healthcare to continue generating positive health outcomes while adapting to new ecological, cultural, and economic realities.

\section{Key messages}

- The economic and social transitions required to maintain planetary health will increasingly require uncomfortable transformations within healthcare systems

- To ensure economic wellbeing does not come at the cost of environmental harms, healthcare will need to focus on doing enough, not doing everything possible

- Reducing economic complexity could limit the scope of available interventions or technologies

- Transformed health systems can still deliver improved health outcomes for individuals and populations despite these challenges

Contributors and sources: MH has worked on health financing, planning, and economics as a senior policy maker and researcher in the UK, Central Asia, South Africa, and Australia. His current research on health system sustainability combines insights from health economics and ecological economics. KZ's work on health systems brings together theories from anthropology, sociology, ecology, and ecological economics. MH proposed the initial idea for the article; its preparation and writing were a shared effort. MH is the guarantor of the article and the corresponding author.

Competing interests: We have read and understood BMJ policy on declaration of interests and have no interests to declare.

Provenance and peer review: Not commissioned; externally peer reviewed.

This article is part of series (https://www.bmj.com/anthropocene). Open access fees were paid by Deakin University.

We acknowledge the Wurundjeri people of the Kulin nation and the Neutral, Anishinaabeg, and Haudenosaunee peoples as the traditional custodians of the lands on which this work was undertaken.

Hensher M, Tisdell J, Canny B, Zimitat C. Health care and the future of economic growth: exploring alternative perspectives. Health Econ Policy Law 2020;15:419-39. doi: 10.1017/S1744133119000276 pmid: 31685052

2 Steffen W, Broadgate W, Deutsch L, Gaffney O, Ludwig C. The trajectory of the Anthropocene: the great acceleration. Anthropocene Review 2015;2:81-98.doi: 10.1177/2053019614564785

3 Steffen W, Richardson K, Rockström J, etal. Sustainability. Planetary boundaries: guiding human development on a changing planet. Science 2015;347:1259855.

doi: 10.1126/science. 1259855 pmid: 25592418

4 Daly $\mathrm{H}$. A further critique of growth economics. Ecol Econ 2013;88:20-4.doi: 10.1016/j.ecolecon.2013.01.007

Zywert K, Quilley S. Health systems in an era of biophysical limits: the wicked dilemmas of modernity. Soc Theory Health 2018;16:188-207. doi: 10.1057/s41285-017-0051-4

6 Ward JD, Sutton PC, Werner AD, Costanza R, Mohr SH, Simmons CT. Is decoupling GDP growth from environmental impact possible?PLoS One 2016;11:e0164733. doi: 10.1371/journal.pone.0164733 pmid: 27741300

7 Evans S. UK's CO2 emissions have fallen $29 \%$ over the past decade. World Economic Forum Carbon Brief. 2020. https://www.weforum.org/agenda/2020/03/analysis-uk-s-co2-emissionshave-fallen-29-over-the-past-decade/

8 IPBES. The global assessment report onbiodiversity and ecosystem services: summary for policymakers. Intergovernmental Science Policy Platform on Biodiversity and Ecosystem Services, 2019.

9 Stoknes PE, Rockstrom J. Redefining green growth within planetary boundaries. Energy Res Soc Sci 2018;44:41-9doi: 10.1016/j.erss.2018.04.030

10 Daly H. From uneconomic growth to a steady state economy. Edward Elgar, 2014 74doi: 10.4337/9781783479979

11 Kallis G, Kerschner C, Martinez-Alier J. The economics of degrowth. Ecol Econ 2012;84:172-80doi: 10.1016/j.ecolecon.2012.08.017

12 Hickel J, Kallis G. Is green growth possible?New Polit Econ 2019:25:469-86doi: 10.1080/13563467.2019.1598964 
13 Kovacic Z, Spano M, Lo Piano S, Sorman AH. Finance, energy and the decoupling: an empirical study. J Evol Econ 2018;28:565-90.doi: 10.1007/s00191-017-0514-8.

14 Smil V. Growth: from microorganisms to megacities. MIT Press, 2020

15 O'Neill DW, Fanning AL, Lamb WF, etal. A good life for all within planetary boundaries. Nat Sustain 2018;1:88-95doi: 10.1038/s41893-018-0021-4

16 Zywert K, Quilley S, eds. Health in the Anthropocene: living well on a finite planet. University of Toronto Press, 2020doi: 10.3138/9781487533410

17 Masters R, Anwar E, Collins B, Cookson R, Capewell S. Return on investment of public health interventions: a systematic review. J Epidemiol Community Health 2017;71:827-34. doi: 10.1136/jech-2016-208141 pmid: 28356325

18 Bertram MY, Sweeny K, Lauer JA, etal. Investing in non-communicable diseases: an estimation of the return on investment for prevention and treatment services. Lancet 2018;391:2071-8. doi: 10.1016/S0140-6736(18)30665-2 pmid: 29627159

19 Borowy I. Degrowth and public health in Cuba: Lessons from the past?J Clean Prod 2013;38:17-26. doi: 10.1016/j.jclepro.2011.11.057

20 Brownlee S, Chalkidou K, Doust J, etal. Evidence for overuse of medical services around the world. Lancet 2017;390:156-68. doi: 10.1016/S0140-6736(16)32585-5 pmid: 28077234

21 Saini V, Brownlee S, Elshaug AG, Glasziou P, Heath I. Addressing overuse and underuse around the world. Lancet 2017;390:105-7. doi: 10.1016/S0140-6736(16)32573-9 pmid: 28077230

22 Pretty J, Barton J, Bharucha ZP, etal. Improving health and well-being independently of GDP: dividends of greener and prosocial economies. Int J Environ Health Res 2016;26:11-36. doi: 10.1080/09603123.2015.1007841 pmid: 25670173

23 WHO. Ten threats to global health in 2019 Geneva. 2019. https://www.who.int/emergencies/tenthreats-to-global-health-in-2019.

24 Mazzucato M. The entrepeneurial state: debunking public vs private sector myths. Anthem Press, 2013.

25 WHO. Antibacterial agents in clinical development: an analysis of the antibacterial clinical development pipeline. World Health Organization, 2019.

26 Farley J, Kubiszewski I. The economics of information in a postcarbon economy. In: Elliott P, Hepting D, eds. Free knowledge: confronting the commodification of human discovery. University of Regina Press, 2015: 199-222.

27 O'Connell M. To be a machine: adventures among cyborgs, utopians, hackers and the futurists solving the modern problem of death. Doubleday, 2017.

28 Hensher M. A beginner's guide to avoiding bad policy mistakes in the Anthropocene. In: Orr C), Kish K, Jennings B, eds. Liberty and the ecological crisis: freedom on a finite planet. Routledge, 2019: 207-19. doi: 10.4324/9780429327100-14

29 Bailey D. The environmental paradox of the welfare state: the dynamics of sustainability. New Polit Econ 2015;20:793-811. doi: 10.1080/13563467.2015.1079169

30 Ruckert A, Huynh C, Labonté R. Reducing health inequities: is universal basic income the way forward?J Public Health (Oxf) 2018;40:3-7. doi: 10.1093/pubmed/fdx006 pmid: 28158715

31 Chwalisz C, Diamond P, eds. The predistribution agenda: tackling inequality and supporting sustainable growth. Policy Network/IB Tauris, 2015.doi: 10.5040/9780755621774

32 Moscrop D. In Canada, an inspiring movement emerges in response to coronavirus. Washington Post2020 Mar 24. https://www.washingtonpost.com/opinions/2020/03/24/canada-an-inspiringmovement-emerges-response-coronavirus/

33 Hensher M, Tisdell J, Zimitat C. "Too much medicine": insights and explanations from economic theory and research. Soc Sci Med 2017;176:77-84 doi: 10.1016/.j.socscimed.2017.01.020 pmid: 28131024

34 Thornton J. Clinicians are leading service reconfiguration to cope with covid-19. BMJ 2020;369:m1444. doi: 10.1136/bmj.m1444 pmid: 32273263

35 van Elsen T, Günther A, Pedroli B. The contribution of care farms to landscapes of the future: a challenge of multifunctional agriculture. In: Farming for health: green-care farming across Europe and the United States of America. Springer, 2006:91-100. doi: 10.1007/1-4020-4541-7_7

36 Le Quéré C, Jackson R, Jones M, Smith A, Abernethy S, Andrew R, et al. Supplementary data: temporary reduction in daily global CO2 emissions during the COVID-19 forced confinement (Version 1.0). Global Carbon Project, 2020. https://www.icos-cp.eu/gcp-covid19. doi: 10.18160/RQDW-BTJU.

37 Hepburn C, O'Callaghan B, Stern N, Stiglitz J, Zenghelis D. Will COVID-19 fiscal recovery packages accelerate or retard progress on climate change? Oxf Rev Econ Policy2020;36(suppl 1).s359-81. doi: 10.1093/oxrep/graa015

38 Alexander S. Basic and maximum income. In: D’Alisa G, Demaria F, Kallis G, eds. Degrowth: a vocabulary for a new era. Routledge, 2015.

This is an Open Access article distributed in accordance with the Creative Commons Attribution Non Commercial (CC BY-NC 4.0) license, which permits others to distribute, remix, adapt, build upon this work non-commercially, and license their derivative works on different terms, provided the original work is properly cited and the use is non-commercial. See: http://creativecommons.org/licenses/bync/4.0/. 